\title{
Challenging the Comfort Zone: Self-discovery, Everyday Practices and International Student Mobility to the Global South
}

\author{
LAURA PRAZERES ${ }^{1}$ \\ Department of Geography and Sustainable Development, University of St Andrews, St \\ Andrews, Fife, United Kingdom
}

\begin{abstract}
This paper scrutinises the underlying motivations of short-term international students by unpacking the notion of 'leaving the comfort zone' for self-discovery and selfchange. Drawing on semi-structured interviews with Canadian exchange students volunteering and studying in the Global South, the paper contributes to scholarship on everyday and emotional geographies of international student mobility and wider debates in mobility by examining how emotions of comfort and discomfort as well as everyday practices are productive for self-discovery, belonging, home-making and distinction. It reveals how students align the boundaries of their comfort zone and an un/reflexive self along the international and imaginative borders of the Global North/South. Contrary to tourism and mobility studies, I argue that students view everyday life and their relative immobility while abroad as both a distinctive and reflexive exercise. I suggest that students want to extend the boundaries of their comfort zone and their sense of 'home' to the Global South.
\end{abstract}

KEY WORDS: International student mobility, comfort, sense of self, everyday practices, home, emotions, self-discovery.

\section{Introduction}

Travel is more than just movement towards a destination; it is often regarded as a meaningful journey of self-discovery and a step outside of the 'comfort zone'. While mobility is a search for self and meaning (Wilson and Harris 2006), it is also an intensely emotional experience that affects and is affected by emotions such as comfort and discomfort. Young people commonly use international mobility to move away from a place, feeling or situation of comfort with the aim to discover themselves and grow as individuals. Thus, as they depart from the comfort zone both in a figurative and physical sense - they may encounter discomfort, with many increasingly finding their arrival within the geographical and imaginative borders of the Global South (Breen, 2012). Although the comfort zone is well-documented in the literature on travel and outdoor education, it is less so within the area of international student mobility despite its relevance and prevalence, and as replete as travel narratives are with 'self'-centred motivations (pun intended), few studies have sought to unpack the conceptual and geographical underpinnings of self-discovery and self-development. Indeed, van 't Klooster et al. (2008) suggest that research should examine these notions in more depth with respect to educational travel. This paper therefore contributes to a growing literature on international student mobility.

Student motivations to study or intern abroad are as multifarious in scope as they are heterogeneous in experiences. The reasons propelling students' movement to and from particular places are diverse and complex. International student mobility is framed within the

\footnotetext{
${ }^{1}$ Correspondence Address: Department of Geography and Sustainable Development, University of St Andrews, Irvine Building, St Andrews, Fife, KY16 9AL, United Kingdom. Email: Laura.Prazeres@standrews.ac.uk
} 
literature in terms of career development and benefits for prospective employment (Findlay et al. 2005; Robertson et al. 2011), but also as an opportunity for adventure (King et al. 2011; Waters and Brooks 2010) and for personal development (Gmelch 1997; Lesjak et al. 2015). In fact, academic and professional goals are often cited as secondary to personal development within short-term international student mobility (Van Mol and Michielsen 2014) and this study is no different. Lesjak et al. (2015) point out that much of the work in this area is concerned with identifying students' motivations rather than critically examining their underlying meanings. Although Waters (2012) highlights that the dearth of work on internationally mobile students is finally being addressed within geographical scholarship, King and Raghuram (2013) remind us that much work is still needed regarding theorisations and empirical contributions within international student mobility. Notably, emotions and affect are key facets of international mobility (Conradson and McKay 2007), yet emotional geographies remain virtually absent within international student mobility scholarship despite the obvious relevance of emotions within young people's educational travel and the growing body of work on emotions, mobility and migration (Dunn 2010; Walsh 2012). Thus, this paper attends and contributes to a dynamic and growing literature on short-term international student mobility by considering the notions of 'self' and comfort, and how these intersect and change through mobility to the Global South. More specifically, it scrutinises the ubiquitous yet ambiguous notion of 'leaving the comfort zone' and the motivation for self-discovery frequently expressed within international student narratives.

In exploring how notions, emotions and motions of dis/comfort intersect with the self, this paper first sets the contextual scene and the geographical setting of the study by briefly discussing short-term student mobility flows from Canada to the Global South. Second, emotional geographies and international student mobility have become important fields of inquiry, but have yet to fully merge and engage with each other - a gap that this paper addresses. From this point, I discuss how emotions of dis/comfort and the notion of 'comfort zone' figure within geography and international student mobility. Third, the study's methodology is presented. Fourth, drawing on pre-departure interviews with Canadian exchange students in the Global South, this paper excavates assumptions and expectations of self-discovery within short-term international mobility in order to unearth the underlying core motivations and meanings. It also demonstrates that place matters by working through the conceptual boundaries of the 'comfort zone'. The paper concludes by considering how notions and emotions of comfort can be insightful for understanding students' motivations for mobility and wider debates on self, 'home' and distinction.

\section{Student mobility from the Global North to the Global South ${ }^{2}$}

While mobility flows of international students to and within the Global North - and particularly the Western world - are well-represented in the literature (Dolby 2005; Gmelch, 1997; King and Ruiz-Gelices 2003), there is far less work examining the flows of students from the Global North to the Global South. Yet, Loker-Murphy and Pearce (1995) note that young people have played a significant role in redistributing tourism and mobility flows from Europe to the Global South. Indeed, Breen (2012) points out that students from the Global North are increasingly heading to the Global South within the context of short-term mobility exchanges (i.e. study exchanges and internship or voluntary placements). A reason for this is that countries in the Global South are increasingly regarded as the next frontier for international student exchanges due to their uniqueness and distinctiveness (Desforges 1998) and precisely because they are perceived as challenging, 'risky and rewarding' (Elsrud 2001, 598). Countries in the Global South are therefore perceived as the next 'go-to' destinations. However, such a spatial imagination is too often shaped by 'colonial histories and postcolonial imaginaries' (Madge et al. 2009, 42). Despite these new mobility channels and the growing body of work on volunteering in the Global 
South (Diprose 2012; Simpson 2004) student mobility from the Global North to the Global South has been remarkably ignored within the study abroad literature.

Moving beyond the privileging of student mobility within the Global North, the distinctive empirical and geographical focus of this study seeks to extend existing scholarship in the field of international student mobility. Rather than follow the tradition of separating both groups as the literature has done, I have incorporated the accounts of both students studying and volunteering/interning abroad as part of a university exchange programme. This study therefore situates itself within the broader context of short-term student mobility and while I acknowledge the heterogeneity of experiences and motivations between these groups, I demonstrate that both share a common and predominant motivation of leaving the comfort zone for selfdiscovery. I argue that researching the experience of exchange students can allows us to understand how young people intend to use short-term university exchanges (instead of longterm mobility for an entire degree) for self-discovery and personal development, rather than primarily for academic or educational development. International exchanges therefore provide a complex and unique context to examine overlapping and underlying sets of motivations and processes within mobility, as well as add breadth and depth to conceptual inquiries on comfort and the self.

\section{The comfort zone and emotional geographies of international student mobility}

Emotions are mobile and mobility is an intensely emotional experience. Mobility produces and allows for different emotional articulations to take place through and in places, and the emotions felt through mobility can influence our sense of self (Conradson and McKay 2007). Exploring emotional narratives of British migrants in Dubai allowed Walsh (2012) to not only highlight the importance of temporality and spatiality for migrant identities but also how living abroad altered migrants' emotions towards 'home'. Emotional geographies of mobility thus enable us to explore people's mutable feelings of 'home' whilst revealing potential ramifications to people's sense of self. Davidson and Milligan $(2004,52)$ point out that how others project emotions onto us can 'challenge the very boundaries of the self' while Pile (2010) contends that emotions are not bounded; rather, they traverse boundaries. Comfort and discomfort, for instance, are both affective and emotional responses to physical and psychological stimuli which are accentuated by movement through space. Pile (2010) identifies comfort and discomfort as emotions described by geographers and Bissell (2008) is one such geographer who explores the corporeal and definitional ambiguity of comfort while authors in the forthcoming Geographies of Comfort book examine the various conceptual and empirical facets of dis/comfort. Yet, the notion of 'comfort zone' has received no attention from social and cultural geographers despite its evident spatial and emotional references. The ubiquity of the comfort zone within travel and study abroad coupled with geographers growing attention to comfort seems timely if not overdue for conceptual reflections and is a starting point for this article.

The notion of 'comfort zone' is best known within studies of outdoor education (Brown 2008 ) and pedagogy (Boler and Zembylas 2003). Although Brown $(2008,3)$ points out that there appears to be no extant documented theory for the comfort zone within educational and psychological literature, he explains that within adventure education literature the comfort zone 'is based on the belief that when placed in a stressful situation people will respond by overcoming their fear and therefore grow as individuals.' Within pedagogy, Boler and Zembylas $(2003,108)$ describe the comfort zone as 'the inscribed cultural and emotional terrains' shaped by everyday habits, beliefs, values and unconscious assumptions framed within hegemonic structures. Discomfort, on the other hand, can lead to self-discovery and a critical self-reflection of these beliefs and habits. The authors argue for a 'pedagodgy of discomfort' as an 'emotional labor' that involves re-questioning and '(re)constructing one's own beliefs, values and assumptions' $(2003,110)$. Others suggest that the comfort zone is characterised by cultural 
familiarity. For example, some American universities require outgoing students to participate in intercultural pedagogy training designed to 'facilitate student exploration out of their comfort zone and into the complexity of intercultural similarities and differences' (Pedersen 2010, 73).

Mobility to a new place abroad can bring about a powerful journey of the self that is both reflexive and transformative. Studies suggest that extending the boundaries of the comfort zone enables individuals to stretch their sense of self (Brown 2009). Brown $(2009,505)$ notes that 'it is commonly claimed that sojourners undergo a journey of self-discovery as removal from the comfort of the familiar forces them to test and stretch their resourcefulness and to revise their self-understanding.' Galani-Mouta (2000) posits that travel can involve a 're-setting of boundaries' (p. 204) wherein self-discovery and personal change come from 'learning to be more comfortable in uncomfortable situations' (Root and Ngampornchai 2013, 523). While 'leaving the comfort zone' is a common motivation within international student mobility (Chaban et al. 2011; Forsey et al. 2012), it lacks meaning and analysis, often only mentioned briefly or metaphorically. Chaban et al. $(2011,787)$ indicate that one of the main motivations for New Zealanders to sojourn abroad is for the 'challenge of living outside one's comfort zone' and similarly, students from New Zealand in Doyle et al.'s (2010) study were primarily seeking a challenge and personal growth by being outside their comfort zone. Interviews with recently returned Australian students assert that getting out of the comfort zone was an important learning experience of the sojourn abroad (Forsey et al. 2012). However, none of these studies have given any attempt to further explicate its meaning.

Whilst the term is inherently geographical, it remains entirely neglected within geographical scholarship. While a range of emotions are elicited through mobility, this paper focuses on comfort as a predominant feeling expressed by participants within this study. More specifically, it is the prevalence of comfort within participant narratives that steered the research analysis towards a consideration of the emotional dimensions of international mobility. In other words, rather than frame the research agenda through an emotional geographies lens from the outset, the study considers the role of emotions through and specifically because of the emergence of the theme of comfort. An inductive approach has been pivotal in enabling meanings and emotions to emerge around the notion of comfort in a way that reveals how emotional geographies can expand and deepen our understanding of students' motivations and perceptions of mobility. Indeed, mobility influences how we perceive and feel (dis)comfort. If mobility generates and alters emotions and if emotions test the boundaries of the self, then how do emotions and mobility perturb the personal boundaries of the comfort zone? This paper thus explores how dis/comfort and the boundaries of the comfort zone are renegotiated and refigured through international mobility. It contributes a distinct and unique focus to the mobility literature by developing a conceptual understanding of the notion of comfort zone and emotions of dis/comfort not only within international student mobility, but also within wider geographical discourses on mobility, emotions and 'home'.

\section{Methodology}

The findings presented here are part of a larger qualitative longitudinal study on short-term student mobility to the Global South that collected semi-structured interviews with Canadian university students at three stages: pre-departure, in situ at the mid-point, and upon return to Canada. However, this paper draws uniquely on the pre-departure interviews, which queried participants' motivations and expectations of studying or interning in the Global South. Among the 28 participants, 13 were participating in a study exchange at a university in the Global South, while 15 took part in an internship placement with a non-governmental organization in the Global South. While the disproportional number of women (24) to men (4) in this study reflects the uneven gender participation rates of women in international exchanges (Salisbury et al., 2010) and higher rates of female participation in research studies (Galea and Tracy 2007), 
as a female researcher, my gender and positionality may also have influenced the recruitment process (Van Mol et al. 2014). The length of the sojourns ranged from 2 months to 12 months and the destinations were distributed among Latin America and the Caribbean (14), Africa (7) and Asia (7). Participants were recruited at pre-departure orientation sessions with outgoing exchange students at Canadian universities in Ontario and Québec between March 2012 and May 2013. Hence, a mix of Francophone (12) and Anglophone (16) students are represented in the study. Interviews were conducted in participants' language of preference (i.e. English or French) and all quotes are translated into English. Certain expressions and words in French are retained in brackets and italic within the quotes as an original source of reference.

Interviews were transcribed verbatim from the original audio-recordings. A thematic analysis of the interviews was undertaken by reading the transcripts to identify meanings, themes and key words related to mobility motivations and the self. The transcripts were read and re-read to check for overlaps and contradictions. Recurring themes were coded to form categories and these were constantly compared for new emerging and overlapping themes to (re)form core categories. Since semi-structured interviews allowed Borges et al. (2015) to access perceptions and motivations for mobility and enabled Christie (2009) to capture emotions in young people's transitions to university, this method was useful in this study for teasing out nuanced meanings and feelings that participants assigned to their upcoming international exchange. Much like in the empirical findings of this paper, emotions and notions of comfort pervade the research methodology in ways that are also productive for the interview process. Since spatial and contextual comfort during the interview is helpful for reducing stress and eliciting opinions and story-telling, the location of the interviews was considered for its potential to influence participants' feelings in ways that can create a comfortable and open environment for meaning-sharing or meaning-making (Elwood and Martin 2000). I therefore sought to conduct, when possible, pre-departure interviews with participants' in their home environment either face-to-face or via Skype video calls. Online interviews can influence the relationship and emotional distance between the interviewer and the participant, but as Deakin and Wakefield (2013) assert, Skype may also facilitate rapport and participation for those who feel uncomfortable with face-to-face interviews. All interviews were audio-recorded with participants' permission and all names were changed.

\section{The boundaries of the comfort zone along the Global South}

Participants describe their motivation to undertake an exchange abroad as a challenge to 'escape', 'leave' or be 'outside' of their comfort zone. This popular statement and motivation reflects online sources that promote study abroad - particularly to countries in the Global South - as a way to 'challenge the comfort zone' (Sachdev 2013). Meeting with Arianne prior to her 6month study exchange in Chile, she neatly summarises what many other participants have foregrounded:

'It's really stupid but I wanted a bit to set a challenge for myself (me poser un défi) now that I have become quite comfortable (à l'aise) with my life in [Canadian city], and I wanted to leave my comfort zone and really start over.'

Arianne feels that leaving her current Canadian city for a different country and city not only presents a novel experience and personal challenge, but her comment about wanting to 'start over' suggests a perceived opportunity for creating a new lifestyle and/or reinventing herself. For participants, the international setting of the internship offers a new set of difficulties and therefore, a higher level of challenge than staying in their current city in Canada. Place, it would seem, gives value to particular (e.g. cultural and emotional) forms of struggles. It also suggests that overcoming such difficulties necessarily implies some kind of reward. Set for a 2-month 
internship in Rwanda, Brianne is one participant who has never lived away from her parents' home. She echoes the importance of place for her the comfort zone and its potential reward in the form of introspection:

'I think the best way to sort of learn about yourself is when you're not in your comfort zone. ... I think being in a different country, a different city, it's like, can I do this on my own? I can be independent in [hometown] no problem, it's easy. I can do it in any Canadian city; it's not going to be difficult. I mean, difficult yes, but it's not not doable, whereas living abroad, it doesn't work for everybody.'

Brianne believes that geographical relocation and hence, leaving the comfort zone, will test personal attributes and foster self-exploration. Yet, in pointing out that living abroad 'doesn't work for everybody', she is not only highlighting the challenge of her upcoming international endeavour, but also implying that emotional capacity is a key factor that determines whether individuals will - as the colloquial saying goes - 'make it or break it'. Brianne defines the comfort zone as a space delimited by Canadian national borders. The physical, and possibly even virtual or imaginary act of crossing over international boundaries is simultaneously a step outside of physical and emotional boundaries of comfort and familiarity (i.e. the comfort zone). Galani-Mouta $(2000,205)$ explains that 'the issue of people going places is important because it relates to notions of boundary, inside and outside, distance and difference, all of which enter into the construction and renegotiation of the self.' This is significant, since for Brianne and other participants, the boundaries of the comfort zone parallel inter/national borders and are believed to give access, or at least the potential, to tap into a reflexive mode of self-discovery. Jenkins (2015, 13-14 original emphasis) indicates that 'a boundary is simultaneously where something stops and something else begins, and something that indicates where something stops and something else begins' and here, international and imaginative geographical boundaries/borders indicate where the reflexive self begins and ends. From this perspective, the notion of the comfort zone highlights two things: that space and place are important for a sense of self; and, that the boundaries of a un/reflexive self are drawn along, and aligned with, international and imaginative borders of un/familiarity. Self, place and comfort thus interact and intersect within and between un/familiar geographical borders.

However, far from merely a distant location, Steve explains how the comfort zone is necessarily about cultural distance. Having visited and lived in multiple countries for several months at a time, his 3-month internship in Nepal will add to his growing list of places visited around the globe:

'I think it's more culturally than it is a physical thing. ... The farther you move away from your culture ... it's a lot further outside of your comfort zone. ... Comfort zone doesn't necessarily mean putting your life in danger. It's like not being able to speak to the locals, not being able to read the local signs. There's always the possibility of getting lost (laughs).'

For Steve, the challenge of 'leaving' the comfort zone is understood in terms of a departure from cultural and physical familiarity. The degree of unfamiliarity and thus, the level of difficulty of the challenge increases with both geographical and cultural distance. Indeed, when I ask Pierre (who has never lived abroad) at what level leaving the comfort zone is a challenge, he quickly responds:

'Everything. Physical, intellectual, moral, ethical, political; you wouldn't get that set of challenges here. ... It's different. The whole lifestyle is different, everything needs to be 
relearned; how you speak to people, how you see life... everything. That's leaving your comfort zone.'

Since 'here' presumably refers to Canada as a country and a national space of familiarity, Pierre looks beyond national and familiar borders for a wider spectrum of challenges that he feels are only attainable outside of Canada. As such, the notion of the comfort zone described by participants takes on a multitude of meanings through a complex amalgamation of physical and emotional factors. Steve and Pierre's differing experiences abroad (Steve lived in multiple countries while Pierre has never lived outside Canada) could explain why Pierre paints a broader definition of the comfort zone in comparison to Steve. Participants' comfort zone will likely differ according to prior travel experiences, ancestry, gender and other background characteristics that position them differently within a certain social milieu. Although participants have different comfort zones, there seems to be a common thread and consensus that the comfort zone is constituted by feelings of comfort based on a familiar space and cultural everyday practices.

Just as Bissell $(2008,1697)$ calls for geographers to attend to the 'nuances' and complexities of comfort, I argue that the comfort zone is useful for understanding how young people attach internal (emotional) and external (geographical) boundaries to their sense of self. It suggests that a sense of self is embedded in familiar and comfortable (physical and emotional) spaces and places and, more specifically, how unfamiliarity of a place, as well as emotional and physical discomfort, are perceived as productive for self-discovery. The boundaries of the comfort zone are therefore uneven, diffuse, malleable, permutable and subject to change depending on un/familiar and un/comfortable physical, cultural and emotional contexts.

However, if the nature of the challenge arises from the relocation to a different place and culture, why not choose to intern or study in a different province or region in Canada? Certain provinces and territories such as Québec and Nunavut are recognised as culturally and linguistically unique within the country. I ask Christina, preparing for her upcoming 10-month study exchange in Tanzania, why not choose to study in Québec instead? She replies:

'It's almost too close. It's like an easy get-away. Like, all of the cultural norms are pretty much the same. ... I enjoy the difference. I'm just so used to being here that I enjoy being pushed... Like this sounds weird, but even if I went to France, it would be like, well, whatever; it's not enough of a challenge.'

Christina highlights the importance of relative distance from everyday physical and cultural familiarity in her pursuit of a challenge. This reflects a comment made by a participant in Ryan and Mulholland's $(2014,594)$ study of French expats who express that the proximity of London to France felt like 'living in the same country.' Québec, in this perspective, is simply too close for discomfort. While there is also discomfort within Canada and the Western World, many participants suggest that the boundaries of their comfort zone stretch beyond Canadian and Western borders; in fact, they are even drawn along the limits of an imagined Global South. Participants dismiss cultural diversity between nations within the Western world as too similar to be conducive to self-discovery, effectively dichotomising and homogenising both the Global North/South. Imaginative geographies of the Global South are associated with greater risks and everyday challenges and are thus viewed as affording more rewarding and transformative qualities (Ansell 2008; Elsrud 2001). As such, the Global South is sought out as a destination that extends beyond the comfort zone of the Western world, where young people can increase their cultural and geographical distance from familiar home environments with the aim to exercise a reflexive and distinctive self. I thus argue that the Global South is viewed as a space 
where discomforts are productive for self-discovery. Following this thread, the next section teases out the relationship between the comfort zone and self-discovery.

\section{'Leaving' the comfort zone for self-discovery and self-change}

Bissell $(2008,1697)$ observes that 'to remain within our "comfort zone" is something that we are led to believe will at best impede our progress.' This popular belief is what underlies participants' motivations and expectations of leaving the comfort zone. They believe that stepping outside the boundaries of their comfort zone is a path towards self-discovery, selfdevelopment and even self-change. In her study of Erasmus students in Europe, MurphyLejeune $(2002,30)$ notes that while living abroad students 'discover' new aspects of their self and participants in this study expect no less. Geographical relocation to another city or country involves both physical and emotional discomfort, and the Global South in particular is viewed by many as a place of discomfort. This view is exemplified by Marilyn, a student preparing for her 2-month internship in Sierra Leone. Speaking to me from the comfort of her home in Canada, Marilyn compares her hometown and Sierra Leone as geographically opposing spaces of comfort:

'What I have is a very comfortable life in [Canadian hometown], so I think that I'm going from one end to the extreme other.'

This element of discomfort is also expressed in her expectations of everyday life in Sierra Leone:

'I know I'm going to see things that are going to make me uncomfortable and I don't know how that's going to change me or inspire me.'

Feeling uncomfortable, however, is regarded in this context as a desirable feeling that can inspire self-change. Marilyn is not questioning if the discomforts of Sierra Leone will change her, but how. This demonstrates that place, and specifically the Global South, matter (Keese 2011). Participants imagine and project assumptions onto countries in the Global South based on representations and conditions that suit their needs (Korpela 2010). Hence, by representing everyday conditions in the Global South as 'uncomfortable' and therefore different from her 'comfortable' life in Canada, Marilyn constructs and frames an image of Sierra Leone that corresponds to popular travel discourses of self-change and to the Global South as a 'challenging' place. The challenge and discomforts envisioned of everyday life in the Global South come from the anticipated struggles of trying to fit in a 'different' environment. Learning to 'fit in' a new spatial, social and/or cultural context with differing sets of normative dispositions 'creates a sense of discomfort [that] can challenge or provoke reflection on our mode of relating to others, sometimes acting as a catalyst for change' (Valentine and Sadgrove 2012, 2060) and this is what drives participants to study or intern abroad. Lucy explains the motivations behind her upcoming study exchange in Turkey and the desired escape from comfort:

'It's kind of a like a little escape, and I find it makes you realise different things about you. When you go through the same routine every day at home, as comfortable and as happy as you are with it, you're not really challenged in different ways. ... so I feel like it really helps you figure stuff out about you. And it gives you a chance to be away from everything and kind of discover yourself... as cheesy as that sounds.'

Lucy demonstrates how escaping the comfort zone is thought as an emotional challenge that can lead to self-discovery. Comfort and familiarity of everyday life in Canada seem to imply a 
personal state of ease and predictability that hinders her ability to discover and reflect on her 'self'. She therefore feels that her upcoming sojourn in Turkey offers an opportunity to remove herself (even if temporarily) from familiar places and people that frame her image and sense of self. For Lucy, the step away from familiarity and comfort is a step closer to self-discovery. Yet, despite their best intentions and efforts, participants may never succeed to fully escape their comfort zone, and may even retreat to it (see Prazeres, forthcoming). There is always an inherent comfort in knowing that the sojourn abroad is temporary (Brown and Aktas 2011).

Removal from the comfort zone through geographical mobility is considered not only as a state of discomfort but also of physical and emotional disorientation. This is both a literal and figurative notion that has been expressed by some participants. Amélie, another participant that has never lived abroad, describes her anticipation of living for 3 months in Peru:

'I associate a different place with leaving my comfort zone and of disorienting myself (dépayser). Maybe of creating a distance with your own life to be able to have an outside perspective. Maybe I will make changes with my life upon return. Every time I return from travels, I come back with new convictions or new changes for life, each time. And in relation to what I've seen abroad, in relation to what I want for myself. Going to another place, it's a nice moment of reflection. Travel allows tremendously for reflection.'

Researcher: 'What does this upcoming experience mean to you?'

'It represents for me a way of being better. Just a perspective in the way of improving oneself.'

Amélie is confident that in losing her bearings geographically she will find her 'self' introspectively. This reflects Li's (2010) study in which time spent in a different culture allowed travellers to revise and expand their sense of self and discover latent attitudes and beliefs that would have remained hidden in the familiarity of their home-place. Similar to what MurphyLejeune describes of international students, Amélie believes that 'migration and mobility create the necessary distance, a space from which it becomes possible to observe habitual assumptions from the outside' $(2002,24)$ and, in doing so, would allow her to 'absorb new habits when they seem better than her own' $(2002,100)$. By interning in Peru for 3 months, Amélie is hoping that geographical disorientation will lead to a personal reorientation (Noble 2013). Participants feel that leaving the comfort zone for an unfamiliar environment enables reflection and introspection that allows them to reshape, pick or keep the characteristics, views and values that they see fit or desirable for them. This chimes with a 'do-it-yourself biography' in which young people studying and working abroad use their sojourn to construct individual biographies (Findlay et al. 2006, 302).

Once again, the notion of distance - both physical and emotional - is regarded as conducive for self-reflexivity. Discomfort, distance, disorientation and difference intersect in ways that participants believe can create the necessary (or at least favourable) conditions to generate self-discovery and personal change. Distance, as I discussed earlier, is always relative and suggests proximity to something else. Indeed, participants intend to use mobility with dual aims: to distance oneself away from comfort and familiarity; and, to move closer to difference. Difference here is understood in terms of a different place, people and practices, and is associated with a changed and different self. The expectations and perceptions of self-change are thus mediated by inner and outer positions: by negotiating (metaphorically and emotionally) the inner and outer boundaries of the comfort zone; and, by navigating (physically and imaginatively) international borders. Having considerable prior experience navigating inside and 
outside of many international borders, Rachel describes what her upcoming year-long study exchange to India represents to her:

'It means that I will probably be a very different person at the end of the experience than I was before. Even at the half-way point I will probably be feeling very different and I will have already grown so much.'

Rachel expresses with some authority and confidence the self-change she anticipates through her one-year study sojourn in India. While the repetitive use of the term 'different' in the interviews might be due to lack of a better word, it more importantly indicates what participants view as a consequence of proximity to difference; that is, participants believe that encounters with difference necessarily lead to a different self. I suggest that they seek out encounters with difference in order to feel and be different. However, I assert that participants 'reproduce a potentially naïve assumption that contact with "others" necessarily translates into respect for difference' and a changed self (Valentine 2008, 325). Even participants where this exchange will be their first time residing abroad carry an expectation that studying or working abroad will result in self-discovery and self-change. This commonly held belief exhorted by North American travel discourses and online study abroad rhetoric likely influences and informs students' expectations and motivations for international mobility (Bishop 2013).

In the next section, I probe further into the notions of comfort, difference and everyday practices to unpack the underlying motivations and strategies of participants for leaving their comfort zone. By taking everyday life and practices as a starting point, I demonstrate how participants intend to employ and reconcile dualistic notions of dis/comfort, un/familiarity, the extra/ordinary and difference/sameness to not only incite self-discovery and self-change, but to expand their comfort zone and sense of 'home' in order to attest to a narrative of self-change and distinction.

\section{Expanding the comfort zone through everyday practices abroad}

This paper has thus far shown that participants want to leave the comforts and familiarities of the Western world in search for a larger cultural gap in order to incite self-discovery and selfchange. Although they desire to escape the comforts of their everyday life in Canada and encounter greater difference in the Global South, the following two sections will demonstrate that they are just as eager to engage in mundane practices abroad as a way to, on the one hand, effect self-discovery and self-change and, on the other, to expand a sense of comfort and 'home' to countries in the Global South.

The tourism and travel literature has shifted from examining the reflexive potential of escaping the everyday through travel and tourism to arguing that the everyday is imbricated in travel/tourism practices and thus much of travel/tourism is largely unreflexive (Edensor 2007; Larsen 2008). I take both these points to argue that students envision their upcoming mobility and relative immobility in a new place as a reflexive exercise (or, at least, having the potential for reflexivity) precisely because it will be embedded in the everyday, but in a different everyday spatial and cultural context. My interviews reveal that students perceive the mundane, ordinary practices abroad as exotic because they exude a sense of authentic localness that they wish to tap into. Not only are they searching to engage with the everyday abroad as a way to induce self-discovery and self-reflection, but ultimately, to achieve a level of comfort and of unreflexivity as a testament of their new cultural capital and sense of local belonging.

\section{Extra/ordinary everyday practices}

While the everyday is most commonly associated with the ordinary, the banal, the taken-forgranted and the habitual, Pink $(2012,28)$ argues that we need to resist conceptualising the 
everyday as static or mundane and instead, view it as 'a dynamic and changing site'. The everyday may appear dull and unchanging, but for my participants everyday activities in a foreign place abroad acquire an exotic flair and hold the potential for self-change. Unlike 'roundthe-world travellers' (Germann Molz 2010) and North American students on short-term study exchanges in Europe in which the challenge is to visit as many countries as possible during their time abroad (Gmelch 1997), my participants express a stronger interest in the local daily routines and activities of their host place; that is, they are most looking forward to the everyday living rather than travelling aspect of their exchange. Sophie, for example, describes to me how everyday life abroad is part of what attracts her to participate in her upcoming 3-month internship in Guatemala:

'It's so exciting! I find that when you live abroad, I mean, every situation is different and every country is a different experience, but even just going to buy bread is exciting. It's an adventure, whereas here, it's something you have to [do].'

For Sophie and other participants, it is not so much the everydayness per se that propels them to escape Canada; rather, it is the unfamiliarity and novelty of everyday practices in a different cultural place that lures them abroad. I argue that activities and practices considered ordinary at home are regarded as extraordinary abroad.

Juxtaposing familiar everyday practices onto an unfamiliar place can disrupt the habitual in a way that can provoke and enable us to re-apprehend the familiar through a different perspective. Habits and unreflexive modes of thinking and living can therefore be brought to our awareness and re-evaluated. And this is the challenge expressed by participants and hence, how they intend to incite self-discovery and self-change: through an engagement with everyday life and practices abroad. In the previous section, Christina expressed how cultural norms in other countries of the Western world are still too similar to her life in Canada to be effectively challenging. Here, she explains how life in Tanzania will differ more from that of other countries in the Global North:

'Where I'm going I have to purify every single glass of water I drink, and like, I had to buy a special pen that I stick in the water and that's my water before I can even drink it. And it's just so far removed from my norm that it's awesome. It's a really big challenge in a good way, like, I'm proving myself that I can do it.'

Christina views everyday basic practices and habits in the Global South as challenging and extraordinary. The boundaries of the comfort zone are aligned along the borders of the Global South, but are especially enacted and reinforced through everyday life and mundane practices. Participants use the example of drinking potable water as a mundane habit to illustrate and, more importantly, attest how living in Tanzania is not just different from Canada linguistically or culturally, but differs at the very core of everyday life. Interning or studying in the Global South is considered to be more distant from the comfort zone precisely because everyday practices are seen as more different than within the Global North. And therein lies the foundation of the comfort zone and the underlining motivation for going to the Global South.

Habit instils us with familiarity and comfort, but it can also propel us to travel in order to escape the mundanity of our everyday life at home (Bissell 2014). Since habitual and mundane practices constitute the basis of our familiar day-to-day life, they are therefore a formative base of the comfort zone (Boler and Zembylas 2003). Christina demonstrates how a basic everyday necessity such as potable tap water is largely taken-for-granted in much of the Western world but that in contrast, visiting other areas of the world will require them to reflect on this habitual practice. Participants hope that being confronted with new everyday practices in an unfamiliar place will spark a re-evaluation of their habits and attitudes (Brown 2009). While Snee (2013, 
152) suggests that for gap year travellers the discomfort of 'not fitting in' may lead to reflexivity, the next section demonstrates how participants' desire to engage in everyday practices abroad is not only to exercise self-reflexivity, but is part of an underlying motivation to 'fit in' to their new 'home'.

\section{Expanding the comfort zone for home-making and distinction}

If mundane practices and habits lay the foundation for the comfort zone in such a way that encountering unfamiliar spaces and practices can provoke a process of self-discovery, then what happens when the appeal of the extraordinary everyday abroad becomes, well, ordinary? What happens when the unfamiliar becomes familiar? While the likelihood of this fully happening is debatable, the answer is this: a new sense of comfort. Participants want to become comfortable in the uncomfortable (Root and Ngampornchai 2013) and despite the apparent contradiction this seems to be part of a larger anticipated process of self-development and home-making. More specifically, a two-fold process that expects first, initial encounters with unfamiliar and extraordinary practices to spark self-discovery and change, and second, eventual familiarity of these practices over time to extend the boundaries of the comfort zone and create a new sense of 'home'. I suggest that it is not just the self that is transformed through mobility, but the very feelings and idea of comfort and 'home'. I further suggest that it is not only mobility that may enable these transformations, but relative immobility in the same place. Marilyn, for instance, affirms that her upcoming 2-month sojourn is 'a good length of time to feel like you have a new home somewhere else.' She believes that time - and conveniently, the length of her sojourn - is necessary for establishing a new sense of 'home'. However, in Christina's view, even four months is too little time. Instead, she explains why longer sojourns are more effective for creating a sense of 'home':

'I didn't want to be there for four months. I thought that that would be too short, because that would give me barely enough time to get to know things, ... So this way, I have a lot longer to make myself comfortable and to make friends and to get into it, ... I will have established friendships and a life, and I'll know what I'm doing. I won't be a tourist. I feel like at four months you're still kind of an outsider.'

Christina views her 10-month study exchange in Dar es Salaam, Tanzania, as a way to establish 'a life' in her host place, one that distinguishes her from 'outsider' tourists (and shorterterm exchange students) and situates her inside everyday local life with all the knowledge, perks and comforts that it entails. Indeed, she states with certainty that she 'won't be a tourist', as though the length of her exchange ensures this 'insider' status. She explains further:

'I feel there's a comfort level with being more than a tourist. ... I want to fit in. I want to feel like I can give people directions ... I want to know where the grocery store is and the best place to get this... I just feel like you have to live there to see all these things and to know them. ... I want to feel like I know Dar, like it's my buddy, like we go way back and I know all this about it, you know, and I think that's why I want to be there for that length of time.'

Local knowledge gained over time imparts a sense of comfort and confidence that might incite Christina to speak about the everydayness of place with a certain sense of authority. Time will allow her to accrue familiarity, comfort and symbolic capital in a way that indicates a quality of 'insiderness' and much of what Christina shares is about feelings and distinctions of being 'in/out of place'. Feeling comfortable in a place is contrasted with the uncomfortable and 'out of place' tourist. Similar to the gap year travellers in Snee's $(2013,151)$ study, my participants expect to negotiate feelings of being 'out of place' and discomfort by acquiring 'insider 
knowledge'. I argue that Christina and others see their relative immobility during their upcoming sojourn - that is, studying or working in the same location - as a means to develop everyday comfort with the aim to create a sense of local belonging and distinguish themselves from tourists and travellers. Brianne describes the sense of anticipation and excitement she draws from the prospect of everyday practices in a different place:

'I think I'm most excited about daily life. ... So it sounds weird, but I'm actually just excited to just like, go on the bus and go to work, come home, do my thing or go to the grocery store ... whereas if you're a tourist, you're there for a short amount of time, not two months. You have to do everything more fast-paced and you're on the go and you don't do normal things because what's the appeal of going to a Rwanda grocery store if you're a tourist? You go see the gorillas. You know what I mean? I don't know, but ya, the mundane things ... I think it's just, again, you get comfortable. ... I don't know what it is about doing normal things that I like, but it's just the idea or feeling that you belong to something that you normally don't belong to, I guess.'

Brianne highlights the importance of comfort for integrating into everyday life and cultivating a sense of local belonging. Comfort here will be used strategically to: become intimate with a place and develop a sense of belonging; and, draw a distinction between what participants view as the tourist 'outsider' and themselves as local 'insiders'. Brianne demonstrates how everyday practices and time are expected to create feelings of comfort and a sense of 'home', something that Amélie is eager to achieve:

'What I'm most looking forward to is to really try to feel "at home" (sentir chez moi). ... I'm excited to be in it, to have passed the discomfort (d'avoir passé l'inconfort). The moments in the beginning you're like, "but why am I here? What was I thinking?" I'm like that for each of my travels, ... but afterwards I make a routine there, but a different routine and one that changes habits. And then you feel good ( $t$ 'es bien), you want to stay there, you don't want to come back to [Canada]. That's what I want, that moment of integration, to feel good. I'm looking forward to it (j'ai hâte). I'm hoping it will happen to me (laughs).'

Amélie expects that the transition from feeling uncomfortable to settling in comfortably in a new place will reposition her from that of an outsider to that of an insider 'at home'. Once she has surpassed the productive and reflexive stage of discomfort, Amélie believes that creating a different everyday routine will reshape and alter her habits. Edensor $(2007,212)$ explains that experiencing a disruption to the everyday 'constantly threatens to undermine the structure laid down by habit'. Participants want to familiarise themselves with the unfamiliar to the point that they no longer flinch at the differences; that is, where local everyday practices become unreflexive. In other words, they become habits. The importance of habit as a central geographical concept is that habits are both a product of our engagement with place and productive for place-making and home-making (Dewsbury and Bissell 2015). Acquiring habits and a level of unreflexivity in the everyday abroad can afford a sense of local belonging and cultural capital. While his previous travel experiences in the Global South inform some of his expectations, François describes what he is most looking forward to during his year-long study exchange in Brazil:

'Just being there and picking up little habits of everyday life (prendre des petites habitudes); that's really the stuff that I like. Like adapting myself to the Brazilian lifestyle; I'm really looking forward to that. That's really something that I know I will be able to integrate myself well (bien m'intégrer) ... picking up little habits and living like a 
Brazilian. That's something I'm really looking forward to. I like to ... not assimilate myself, but melt a bit in the crowd (me fondre un peu dans la masse), and I will get there and I will buy myself groceries and make Brazilian stuff, and dress a bit like everyone does; be more like them (laughs).'

François is hoping to acquire local everyday practices in order to 'fit in' and integrate into Brazilian life. As he explains his motivation to study in Brazil, François seems to gradually admit or come to terms with the intention of becoming 'more like them', which is just a step removed from saying that he wants to be one of them. As Murphy-Lejeune $(2002,196)$ highlights, 'what is at stake in this social game is integration into the local society'. Indeed, I suggest that the ultimate challenge is to become an insider elsewhere and arriving at this point is a marker of achievement and cultural capital and thus, distinction. Differentiating themselves from tourists' superficial and ephemeral engagement with place flaunts an ability to engage differently with 'foreign' and particularly 'developing' places. Since Benson $(2010,72)$ explains that 'it is through everyday, mundane practices that local distinctiveness is enacted', my participants intend to normalise unusual mundane practices to establish a sense of belonging and distinction as well as extend their comfort zone beyond western borders. It is a process of assimilating spaces of discomfort and unfamiliarity to be converted into an extended 'home'. Rather than remain outside of the comfort zone for the entirety of their exchange, participants may seek to extend its spatial and practical boundaries into the Global South as a marker of distinction. Since Breen $(2012,99)$ notes that as students move to the Global South 'the boundaries and definitions of migration change', I therefore suggest that mobility can reconfigure the boundaries of the comfort zone and a sense of 'home'.

\section{Concluding remarks}

This paper explored students' motivations to participate on short-term international exchanges in the Global South and showed that students view international exchanges as an opportunity to 'leave their comfort zone' in order to discover and change their sense of self. From this point, it unpacked the notion of 'comfort zone' and scrutinised the underlying motivations of young people to study or intern in the Global South and in doing so, revealed that distance from familiar and comfortable physical, emotional and cultural places is perceived as productive of self-discovery and self-change. Since moving away from comfort and familiarity is positively equated with moving closer to difference, I suggest that students seek to encounter difference in order to feel and subsequently be different. I have also suggested that these motivations and expectations are based on popular assumptions from travel discourses and online study abroad rhetoric that international educational sojourns - particularly to the Global South - inevitably result in self-discovery and personal change. This is because the Global South is perceived as a challenging place with bountiful risks and discomforts, while the Global North is viewed as insufficiently discomforting and dissimilar to Canadian norms to adequately incite a reflexive self. Students draw dualistic borders between the socio-economic contexts of the Global North and the Global South in order to demarcate spatial contexts that are un/productive for selfdiscovery. I therefore argued that students align the boundaries of their comfort zone and hence, a reflexive self along the international and imaginative borders of the Global South. In other words, this study has shown that space and place are important for navigating and negotiating the emotional boundaries of a un/reflexive 'self'.

This paper revealed how imaginative, emotional and everyday geographies of the Global South can underpin students' motivations and expectations of international mobility. It suggested that everyday life is a site of production for the comfort zone and that students expect an engagement with mundane practices abroad will prompt them to re-evaluate and revise their attitudes and habits and hence, their sense of self. Yet, the findings also indicated that students' 
motivations are laced with contradictory (or complimentary) intentions. Instead of, or in addition to, seeking encounters with everyday unfamiliarities and discomforts abroad, I argued that students intend to develop comfort in everyday life abroad as part of an underlying or overriding motive for belonging, home-making and distinction. The ultimate 'challenge' is to make the unfamiliar become familiar and the uncomfortable become comfortable in order to integrate into the local milieu. As such, students expect to negotiate and attenuate feelings of 'in/out of place' and discomfort by acquiring insider knowledge through everyday life practices. Since mundane practices are considered as a gateway to the local insider's life, the everyday abroad takes on an exotic flair. Contrary to the view of mobility as a way to escape the everyday, I argued that students seek out and are fascinated by everyday practices abroad not only because these are exceptional and extraordinary to them, but also because they are very much unexceptional and ordinary to other people. The findings have equally shown that the aim to develop a sense of comfort and familiarity through the everyday abroad is not only to gain a sense of local belonging, but also to gain a new 'home'. Thus, it is not only, or necessarily, the self that is considered to be transformed through mobility, but rather, the feelings and ideas of comfort, familiarity and 'home'. This attests to the importance of place and mobility for mediating feelings of un/familiarity and dis/comfort. I therefore argued that mobility can reconfigure the boundaries of the comfort zone and hence, a sense of comfort and of 'home'. I further suggested that everyday practices are viewed by students as a way to effect self-discovery and personal changes, but equally to extend their sense of 'home' and the boundaries of their comfort zone to the Global South as a marker of distinction.

By exploring the experience of international students in the Global South, this article has revealed how place matters and differs for self-discovery and distinction. Notably, it advances work on international student mobility and distinction by arguing that students regard not so much their mobility abroad as a distinctive or reflexive exercise, but rather, their relative immobility while abroad, precisely because greater time spent in a new place and everyday context can both challenge and instil a sense of comfort and 'home', as well as endow cultural capital. I therefore suggest that comfort not only mediates feelings of belonging and 'home', but also difference and distinction from overly-mobile travellers. In demonstrating that geographies of everyday life and emotional geographies are insightful for understanding young people's sense of self, home-making and distinction, this paper has contributed a novel perspective and added depth to research on international student mobility, but also recent wider debates on $\mathrm{im} /$ mobility. However, since this study is qualitative and inductive with a limited sample of participants, the findings cannot be generalized to Canadian exchange students or exchange students in the Global South. I therefore encourage future research to explore the role of emotions and specifically dis/comfort within other international contexts and mobility flows.

To conclude, this paper has illustrated how emotions are inflected through mobility and affected by place. It advances our knowledge of everyday geographies and emotional geographies by demonstrating how mundane practices and particular emotions such as comfort and discomfort are regarded as conducive for self-discovery, 'home' and distinction. I argue that an inductive approach has allowed for meanings and themes to emerge in a way that has helped conceptualise the notion of comfort zone and thus, develop our understanding of the significance of everyday practices and emotions within students' mobility and sense of self. I echo Bissell's (2008) call for geographers to engage with emotional and spatial conceptions of (dis)comfort as well as the untapped notion of the comfort zone. If, as this study suggested, the comfort zone is expanded to the Global South, then what is the next form of challenge for students? What are the potentially new dimensions, feelings and emotions that can reconfigure the boundaries of the comfort zone? Researching internationally mobile students can therefore be insightful for thinking about, and rethinking motivations for self-discovery and notions of comfort, distinction and of 'home'. 


\section{Acknowledgements}

I would like to thank Katherine Brickell and Katie Willis for their comments on earlier drafts and two anonymous reviewers for their very helpful feedback. I am also very grateful to the students who took part in this study.

\section{Funding}

This work was supported by the Social Sciences and Humanities Research Council of Canada (SSHRC) [\#752-2012-0127]

2 The term 'Global South' is defined broadly by the United Nations Development Program (2004) as countries in Africa, Latin America, Caribbean and Asia with a range of different social, economic and political contexts but with a "shared set of vulnerabilities and challenges" (p. 2).

\section{References}

Prazeres, L. Forthcoming. "Homely Comforts Abroad: Navigating Zones of Comfort in Everyday Geographies of Student Mobility." In Geographies of Comfort, edited by L. Price, D. McNally and P. Crang. Routledge. Ansell, N. 2008. "Third World gap year projects: youth transitions and the mediation of risk." Environment and Planning D: Society and Space 26(2): 218-240.

Benson, M. 2010. 'We are Not Expats; We are Not Migrants; We are Sauliacoise': Laying Claim to Belonging in Rural France. In C. Trundle and B. Bönisch-Brednich. Local Lives: Migration and the Politics of Place. Farnham, Ashgate: 67-83.

Bishop, S.C. 2013. "The Rhetoric of Study Abroad: Perpetuating Expectations and Results Through Technological Enframing." Journal of Studies in International Education 17(4): 398-413.

Bissell, D. 2014. Habits. In P. Adey, D. Bissell, K. Hannam, P. Merriman and M. Sheller (Eds.), The Routledge Handbook of Mobilities. New York, NY, Routledge: 483-492.

Bissell, D. 2008. "Comfortable bodies: sedentary affects." Environment and Planning A 40(7): 1697-1712.

Boler, M. and M. Zembylas (2003). Discomforting truths: The emotional terrain of understanding difference. In P. Trifonas (Ed.), Pedagogies of difference. Rethinking education for social change. New York, Routledge Falmer: 110-136.

Borges, M., Rosado, A., de Oliveira, R. and Freitas, F. 2015. "Coaches' migration: a qualitative analysis of recruitment, motivations and experiences." Leisure Studies 34(5): 588-602.

Breen, M. 2012. "Privileged migration: American undergraduates, study abroad, academic tourism." Critical Arts 26(1): 82-102.

Brown, M. 2008. "Comfort Zone: Model or metaphor?" Australian Journal of Outdoor Education 12(1): 3-12.

Brown, L. 2009. "The transformative power of the international sojourn: An Ethnographic Study of the International Student Experience." Annals of Tourism Research 36(3): 502-521.

Brown, L. and G. Aktas. 2011. "Fear of the unknown: a pre-departure qualitative study of Turkish international students." British Journal of Guidance \& Counselling 39(4): 339355.

Chaban, N., A. Williams, M. Holland, V. Boyce and F. Warner. 2011. "Crossing cultures: Analysing the experiences of NZ returnees from the EU (UK vs. non-UK)." International Journal of Intercultural Relations 35: 776-790.

Christie, H. (2009). "Emotional journeys: young people and transitions to university." British Journal of Sociology of Education 30(2): 123-136. 
Conradson, D. and D. McKay. 2007. "Translocal Subjectivities: Mobility, Connection, Emotion." Mobilities 2(2): 167-174.

Davidson, J. and C. Milligan. 2004. "Embodying emotion sensing space: introducing emotional geographies." Social \& Cultural Geography 5(4): 523-532.

Deakin, H. and K. Wakefield 2013. "Skype interviewing: reflections of two PhD researchers." Qualitative Research 14(5): 603-613.

Desforges, L. 1998. 'Checking Out the Planet': Global representations/local identities and youth travel. In T. Skelton and G. Valentine (Eds.), Cool Places: geographies of youth cultures. London, Routledge: 175-192.

Dewsbury, J.D. and D. Bissell. 2015. "Habit geographies: the perilous zones in the life of the individual." Cultural Geographies 22(1): 21-28.

Diprose, K. 2012. "Critical distance: doing development education through international volunteering." Area 44(2): 186-192.

Dolby, N. 2005. "Globalisation, Identity, and Nation: Australian and American Undergraduates Abroad." The Australian Educational Researcher 32(1): 101-117.

Doyle, S., Gendall, P., Meyer, L.H., Hoek, J., Tait, C., McKenzie, L. and Loorparg, A. "An Investigation of Factors Associated With Student Participation in Study Abroad." Journal of Studies in International Education 14(5): 471-49

Dunn, K. (2010). "Embodied transnationalism: Bodies in transnational spaces." Population, Space and Place 16(1): 1-9.

Edensor, T. 2007. "Mundane mobilities, performances and spaces of tourism." Social \& Cultural Geography 8(2): 199-215.

Elwood, S.A. and D.G. Martin. 2000. "'Placing" Interviews: Location and Scales of Power in Qualitative Research." The Professional Geographer 52(4): 649-657.

Elsrud, T. 2001. "Risk creation in traveling: Backpacker adventure narration." Annals of Tourism Research 28(3): 597-617.

Findlay, A.M., A. Stam, R. King and E. Ruiz-Gelices. 2005. "International Opportunities: searching for the meanings of student migration." Geographica Helvetica 60(3): 192-200.

Findlay, A.M, R. King, A. Stam and E. Ruiz-Gelices. 2006. "Ever Reluctant Europeans: The Changing Geographies of UK Students Studying and Working Abroad." European Urban and Regional Studies 13(4): 291 - 318.

Forsey, M., S. Broomhall and J. David. 2012. "Broadening the Mind? Australian Student Reflections on the Experience of Overseas Study." Journal of Studies in International Education 16(2): 128-139.

Galea, S. and M. Tracy. 2007. "Participation rates in epidemiologic studies." Annals of Epidemiology 17(9): 643-653.

Galani-Mouta, V. 2000. "The Self and the Other: Traveler, Ethnographer, Tourist." Annals of Tourism Research, 27(1): 203-224.

Germann Molz, J. 2010. "Performing Global Geographies: Time, Space, Place and Pace in Narratives of Round-the-World Travel." Tourism Geographies 12(3): 329-348.

Gmelch, G. 1997. "Crossing Cultures: Student Travel and Personal Development." International Journal of Intercultural Relations 21(4): 475-490.

Jenkins, R. 2015. Boundaries and borders. In J. Jackson and L. Molokotos-Liederman. Nationalism, Ethnicity and Boundaries. New York, NY, Routledge: 11-27.

Keese, J.R. 2011. "The Geography of Volunteer Tourism: Place Matters." Tourism Geographies 13(2): 257-279.

King, R., A.M. Findlay, J. Ahrens and M. Dunne. 2011. "Reproducing advantage: the perspective of English school leavers on studying abroad." Globalisation, Societies and Education 9(2): 161-181.

King, R. and P. Raghuram. 2013. "International Student Migration: Mapping the Field and New Research Agendas." Population, Space and Place 19: 127-137. 
King, R. and E. Ruiz-Gelices. 2003. "International Student Migration and the European 'Year Abroad': Effects on European Identity and Subsequent Migration Behaviour." International Journal of Population Geography 9: 229 - 252.

Korpela, M. 2010. "A Postcolonial Imagination? Westerners Searching for Authenticity in India." Journal of Ethnic and Migration Studies 36(8): 1299-1315.

Larsen, J. 2008. "De-exoticizing Tourist Travel: Everyday Life and Sociality on the Move." Leisure Studies 27(1): 21-34.

Lesjak, M., E. Juvan, E.M. Ineson, M.H.T. Yap, and E.P. Axelsson. 2015. "Erasmus student motivation: Why and where to go?" Higher Education. 70(5): 845-865.

Li, M.Z. 2010. "The Voyage of the Self: Experiencing the subjective zone of international travel." Annals of Leisure Research 13(1-2): 191-217.

Loker-Murphy, L. and P.L. Pearce. 1995. "Young Budget Travelers: Backpackers in Australia." Annals of Tourism Research 22(4): 819-843.

Madge, C., P. Raghuram and P. Noxolo. 2009. "Engaged pedagogy and responsibility: A postcolonial analysis of international students." Geoforum 40: 34-45

Murphy-Lejeune, E. 2002. Student Mobility and Narrative in Europe: The new strangers. London, Routledge.

Noble, G. 2013. "'It is home but it is not home': habitus, field and the migrant." Journal of Sociology 49(2-3): 341-356.

Pedersen, P. 2010. "Assessing intercultural effectiveness outcomes in a year-long study abroad program." International Journal of Intercultural Relations 34: 70-80.

Pile, S. 2010. "Emotions and affect in recent human geography." Transactions of the Institute of British Geographers 35: 5-20.

Pink, S. 2012. Situating Everyday Life: Practices and Places. London, SAGE: 166.

Robertson, S., L. Hoare and A. Harwood. 2011. Returnees, student-migrants and second chance learners: case studies of positional and transformative outcomes of Australian international education. Compare: A Journal of Comparative and International Education 41(5): 685-698.

Root, E. and A. Ngampornchai. 2013. "'I Came Back as a New Human Being": Student Descriptions of Intercultural Competence Acquired Through Education Abroad Experiences." Journal of Studies in International Education 17(5): 513-532.

Ryan, L. and J. Mulholland. 2014. "Trading Places: French Highly Skilled Migrants Negotiating Mobility and Emplacement In London." Journal of Ethnic and Migration Studies 40(4): 584-600.

Sachdev, A. 2013. Four Reasons to Try an Unconventional Study Abroad Experience. The Huffington Post. January 30 http://www.huffingtonpost.com/uloop/4-reasons-to-try-anuncon b 2574674.html?utm hp ref=tw

Simpson, K. 2004. "'Doing development': The gap year, volunteer-tourists and a popular practice of development." Journal of International Development 16(5): 681-692

Snee, H. 2013. "Framing the Other: cosmopolitanism and the representation of difference in overseas gap year narratives." The British Journal of Sociology 64(1): 142-162.

Valentine, G. 2008. "Living with difference: reflections on geographies of encounter." Progress in Human Geography 32(3): 323-337.

Valentine, G. and J. Sadgrove. 2012. "Lived difference: a narrative account of spatiotemporal processes of social differentiation." Environment and Planning A 44(9): 2049-2063.

Van Mol, C., R. Mahieu, H.M-L. De Clerck, E. Piqueray, J. Wauters, F. Levrau, E. Vanderwaeren and J. Michielsen. 2014. Conducting qualitative research: Dancing a tango between insider- and outsiderness. In L. Voloder and L. Kirpitchenko (Eds.). Insider Research on Migration and Mobility. Farnham, Ashgate: 69-84.

Van Mol, C. and J. Michielsen .2014. The Reconstruction of a Social Network Abroad. An Analysis of the Interaction Patterns of Erasmus Students. Mobilities 10(3): 423-444. 
van 't Klooster, E., J. van Wijk, F. Go, and J. van Rekom 2008. "Educational Travel: The Overseas Internship." Annals of Tourism Research 35(3): 690-711.

Walsh, K. 2012. "Emotion and migration: British transnationals in Dubai." Environment and Planning D: Society and Space 30: 43-59.

Waters, J. 2012. "Geographies of International Education: Mobilities and the Reproduction of Social (Dis)advantage." Geography Compass 6(3): 123-136.

Waters, J. and R. Brooks. 2010. "Accidental achievers? International higher education, class reproduction and privilege in the experiences of UK students overseas." British Journal of Sociology of Education 31(2): 217-228. 